\title{
Testosterone Greater than 200 ng/dL
}

National Cancer Institute

\section{Source}

National Cancer Institute. Testosterone Greater than 200 ng/dL. NCI Thesaurus. Code C158959.

A semiquantitative finding indicating that the concentration of testosterone in a sample is greater than $200 \mathrm{ng} / \mathrm{dL}$. 